Review Article

\title{
Toll-Dorsal Pathway Regulates Immunity as well as Dorso-Ventral Patterning in Drosophila
}

\author{
MANISH CHAUHAN, PRASHANT PRADHAN and NIROTPAL MRINAL* \\ Laboratory of Molecular Biology, South Asian University, Chanakyapuri, New Delhi 110 021, India
}

(Received on 5 May 2014; Revised on 20 November 2014; Accepted on 12 December 2014)

\begin{abstract}
The identification of the Toll receptor in Drosophila was a major discovery which restructured the paradigm in immunity as well as developmental biology. Toll homologues are present in mammals where they regulate only immunity. However, in flies, same Toll pathway controls two disparate biological processes like embryonic dorso-ventral patterning and humoral immune response. Toll activation by Spätzle is preceded by a proteolytic cascade which is differently regulated in immunity and embryonic development. Signalling downstream to Toll is similar in both processes and eventually leads to the activation of Drosophila homologues of NF-אB proteins; Dorsal and DIF. Toll pathway, in the early embryo results in graded expression of Dorsal protein leading to Dorso-Ventral axis patterning. On the other hand, activation of Toll-Dorsal pathway in the fat-body leads to induction of antibacterial proteins in larval and adult stages. Here, we review the current status of our knowledge of Dorsal pathway in embryonic development and immunity with special emphasis to regulation of target gene/s of the two pathways by Dorsal.
\end{abstract}

Key Words : Dorsal; Toll; DNA Geometry; Dorso-Ventral Patterning; Insect Immunity

\section{Introduction}

Drosophila has been used to dissect genetic basis of different phenotypes and pathways which has helped us in understanding many biological paradigms (Ashburner and Carson, 1986; Fortini et al., 2000). One such paradigm was the discovery of primary role of Toll receptors in embryonic development (Nusslein-Volhard and Wieschaus, 1980; Stein et al., 1991). Subsequent study led to the finding of rest of the downstream genes of dorsal-ventral (D-V) patterning of the embryo. These genes are collectively called as 'the dorsal group of genes' which includes Toll, tube, pelle, cactus, the NFKB homolog dorsal. In the year 1996, it was conclusively shown that 'dorsal group of genes' from the Toll ligand spätzle (Spz) to cactus, is involved in the anti-fungal response in Drosophila (Lemaitre et al., 1996). This set a platform for the discovery and characterization of Toll-like receptors in humans (Medzhitov et al., 1997) establishing the role of the Drosophila Toll-pathway as an evolutionarily conserved mechanism. However, mammalian TLRs are believed to have no role in development (Kimbrell and Beutler, 1998), whereas the Drosophila Toll-pathway is involved both in immunity and developmental processes (Halfon et al., 1995; Lemaitre et al., 1996). Here, we try to understand, how Drosophila Toll-pathway controls both embryonic patterning and immune response.

\section{Toll receptor of Drosophila}

The Toll gene was discovered as a component of DV patterning pathway in Drosophila early embryos (Anderson and Nüsslein-Volhard, 1984; Anderson et al., 1985). Drosophila Toll belongs to a family of

*Author for Correspondence: E-mail: nmrinal@sau.ac.in; Tel.: 011-24195227 
nine paralogues. These are Toll, 18 wheeler $(18 w)$, Toll-3 (also called MstProx), Toll-4, Toll-5 (also called Tehao), Toll-6, Toll-7, Toll-8 (also called Tollo), and Toll-9. Nearly all of the Drosophila paralogues share the same protein architecture. The main difference between the Toll paralogs is in the number of LRRs. The exception is Toll-9, which has a single block of LRRs in the ectodomain, compared to the two blocks seen in the other Tolls (Imler and Hoffmann, 2001). Toll-9 is more closely related to the vertebrate Tolllike receptors (TLRs) than other Drosophila Tolls. Of all Toll proteins of Drosophila, Toll-1 is well studied and is the regulator of $\mathrm{D}-\mathrm{V}$ patterning and immune response.

Toll expresses maternally in early embryos, and zygotically during late embryonic development. Zygotic Toll is expressed in the gut, salivary glands and epidermis (Gerttula et al., 1988). Toll is expressed in migrating cells, and also localises to the sites of contact between the fused epidermal layers at the dorsal midline (Hashimoto et al., 1991). Drosophila Toll receptor is a type I transmembrane protein. It comprises of an N-terminal ecto-domain, middle transmembrane domain, and the C-terminal intracellular domain. The ecto-domain is involved in interaction with other proteins through leucine-rich repeats (LRRs). The LRR domain in Toll is interrupted by two Cysteine rich domains (CRD), thus dividing the LRRs into two blocks. Second CRD is sandwiched between the C-terminal LRR and the transmembrane domain. The intracellular region of Toll contains a Toll/Interleukin-1 Receptor (TIR) domain, which initiates intracellular signalling upon recruitment of adapter proteins.

\section{Toll in Dorso-Ventral Patterning}

Bilateral symmetry in animals results from the presence of the Anterior-Posterior (A/P), and, DorsoVentral (D/V) axis. In Drosophila, D-V patterning pathway gets activated in the maternal egg chamber itself. This pathway is triggered upon somatic expression of Nudel, Pipe and Windbeutel proteins which results in the establishment of ventral cell fates (Stein et al., 1991; Dissing et al., 2001). Pipe is expressed on the ventral side of the follicular epithelium, while Nudel, a protease, is uniformly expressed, (LeMosy et al., 1998; Zhu et al., 2005). Next step is activation of proteolytic cascade involving three proteases, Gastrulation defective (Gd), Snake and Easter, in the perivitelline space (Han et al., 2000; Dissing et al., 2001; Cho et al., 2010). The final proteolytic step releases mature Spz from its inactive pro-peptide form by Easter, after which it binds Toll (Stein et al., 1991; Schneider et al., 1994; DeLotto and DeLotto, 1998; Weber et al., 2003). Cleaved Spz is a dimer, and binding of one Spz dimer to Toll induces receptor homo-dimerization (Gangloff et al., 2008). Recently it has been shown that Toll dimerization is accompanied by endocytosis of this complex (Huang et al., 2010).

On the inner side of the cell membrane, the intracellular TIR domain of Toll interacts with proteins containing Death-domain, which are collectively called as adapter proteins. The three adaptor proteins of Toll pathway are MyD88, Tube and Pelle (Hecht and Anderson 1993; Shen et al., 2001; Kambris et al., 2003). Upon binding of Spz, the TIR-domain of Toll protein forms a homotypic interaction with the TIR domain of MyD88, resulting in the recruitment and activation of the other two adapter proteins (Kambris et al., 2003). Subsequent step in the Toll signalling is the activation of transcription factor, Dorsal. In the cytoplasm Dorsal remains bound to its inhibitor protein called Cactus (Whalen and Steward, 1993). Upon Toll activation, Cactus gets phosphorylated ultimately leading to its degradation by the ubiquitin-proteasome pathway (Bergmann et al., 1996, Reach et al., 1996). In the process, Dorsal gets released and this free Dorsal enters the nucleus to induce or repress target genes.

Regulation of target gene expression by Dorsal is concentration dependent. On the ventral side, concentration of Dorsal is maximum which leads to activation of genes like twist and snail, which specify the mesoderm. On the lateral surface, Dorsal expression tapers down and in this region, it activates sim which specifies meso-ectoderm and rho and sog which specify neuro-ectoderm (Stathopoulos et al., 2002; Stalhopoulos et al., 2004; Biemar et al., 2006). On the dorsal surface, there is no expression of Dorsal 
at all, and here zen is transcribed. Transcription of $z e n$ on the ventral and lateral surface is inhibited by Dorsal (Huang et al., 1997; Stathopoulos and Levine, 2002). The induction and repression of target genes by Dorsal in a concentration dependent manner is regulated by affinity of Dorsal to its binding sequence ( $\kappa B$ motif) (Biemar et al., 2006). It has been proposed that genes like twist and snail which are expressed on the ventral surface (where Dorsal expression is highest), possess low affinity $\kappa B$ motif, while genes like $d p p$ and zen which are expressed on the dorsolateral surface (where Dorsal expression is low) have high affinity $\kappa B$ motifs (Ip et al., 1991; Jiang et al., 1992; Kirov et al., 1994; Dubnicoff et al., 1997; Huang et al., 1997; Stathopoulos et al., 2004; Hong et al., 2008). This is how the gradient of nuclear Dorsal, triggered by ventrally restricted Toll signalling, establishes the dorso-ventral axis in Drosophila embryo.

\section{Toll in Innate Immunity}

Drosophila was shown to have an inducible antibacterial system way back in 1970s (Bakula, 1970; Boman et al., 1972; Boman et al., 1974). Since Drosophila does not have an adaptive immune arm hence this offers the cleanest system to explore humoral response (Tzou et al., 2002). Humoral immune response in Drosophila is mediated by AntiMicrobial Proteins (AMPs) which are produced in the fat body (analogous to mammalian liver) and secreted into the hemocoel (Boman et al., 1974; Lemaitre et al., 1996; Carton et al., 1997; Lemaitre et al., 1997; Basset et al., 2000; Imler and Bullet, 2005). Post bacterial challenge AMP response persists for several days and gives protection against microbes. Drosophila secretes a total of 55 AMPs upon infection by diverse pathogens, which are grouped into seven major classes based on amino acid compositions (Basset et al., 2000; Hultmark, 2003). Prophenoloxidase activation precedes AMP activation and is very critical for insect immunity (Soderhall and Cerenius, 1998). These AMPs are not microbe specific e.g. drosomycin and metchniknowin are active against fungi; attacin, cecropin, diptericin and drosocin are active against Gram-negative bacteria while defensins are active against Gram- positive bacteria (Boman et al., 1974; Lemaitre et al., 1996; Lemaitre et al., 1997; Levashina et al., 1999; Hoffmann, 2003; Brennan and Anderson, 2004; Vierstraete et al., 2004). Activation of these genes requires triggering of the Toll or IMD pathway. Flies deficient for both the Imd and Toll pathways fail to induce any of the known antimicrobial peptides and succumb readily to infection (Lemaitre et al., 1996; Tzou et al., 2002; Hoffmann, 2003; Hultmark, 2003; Brennan and Anderson, 2004). Moreover, activation of either pathway, for example; by over-expressing a pathway component, is sufficient to trigger AMP expression in the absence of infection (Levashina et al., 1999; Georgel et al., 2001; Imler et al., 2004). In this review we will restrict to Toll pathway only.

\section{Extracellular Toll Signalling}

Pathogens on their surfaces express molecules called as Pathogen-Associated-Molecular-Patterns (PAMPs), which are recognized by the host for mounting immune response (Irving et al., 2001). The molecular system in the host that recognizes these PAMPs are called as Pathogen Recognition Receptors or PRRs. Drosophila has two families of PRRs: Peptidoglycan (PGN) recognition proteins (PGRP) and Gram-negative binding proteins (GNBP), which identify distinct PAMPs associated with Grampositive (LYS-type PGN); Gram-negative bacteria (DAP-type PGN); or fungi (Beta-1,3-glucan) (Gottar et al., 2006; Ferrandon et al., 2007). Circulating GNBP3 in hemolymph directly recognizes Beta-1, 3-glucan of fungi and triggers downstream signalling, that finally activates the Toll pathway (Buchon et al., 2009; Levashina et al., 1999). In contrast, the PGN of Gram positive bacteria are recognised by PGRPSA/PGRP-SD and GNBP1. Formation of PAMP and PRR complex activates ModSP (modular of serine proteases) which, in turn, triggers a proteolytic cascade that results in the activation of Spz, the ligand of Toll (Kambris et al., 2006). However, the proteolytic pathway that gets activated in immunity is different from the one that is used in dorso-ventral patterning and this is how the two processes distinctly regulate Toll activation (Fig. 1). The first serine protease in the immune cascade is ModSP, and recognizes both bacterial and fungal PAMPs (Buchon 
et al., 2009). Parallel to ModSP is the protease Persephone (Levashina et al., 1999; Ligoxygakis et al., 2002). Interestingly, Persephone can activate Toll independently of PRRs and is said to respond to 'danger signals' associated with infection (El Chamy, 2006; Kambris et al., 2006). Next protein in the pathway is Sphieroide, a serine protease, which further regulates Spatzle Processing Enzyme (SPE). SPE directly cleaves Spz, releasing the Cys-knot in the Spz, which is critical for binding Toll (Jang et al., 2006).

\section{Intracellular Toll Signalling}

Unlike the extracellular proteolytic cascade, the intracellular signalling cascade activated by Toll during immune response is similar to that in the $\mathrm{D}-\mathrm{V}$ patterning (Gay and Gangloff, 2007). In spite of the similarity in the intracellular signaling, the effector molecule induced in immunity is not Dorsal but its homologue named DIF (Dorsal related Immunity Factor) (Manfruelli et al., 1999; Meng et al., 1999). In the larva, DIF and Dorsal act redundantly, but in the adult, DIF is alone required for mounting immune response and not Dorsal (Rutschmann et al., 2000). The target genes of the Toll-Dorsal signalling pathway during immunity include anti-microbial peptides like drosomycin (Lemaitre et al., 1996).

Toll has an intracellular TIR domain, which recruits adapter proteins, MyD88, Tube and Pelle, to the Spz bound activated Toll receptor (Fig. 1). All three adaptor proteins contain a Death-domain, which is involved in protein-protein interactions leading to formation of a trimer complex (Hecht and Anderson, 1993; Kambris et al., 2003). MyD88 and Tube dimer is localised to the plasma membrane. The Deathdomain of Pelle then binds that of Tube (Sun et al., 2002). Pelle also carries a kinase domain and triggers the activation of Dorsal, possibly through interaction with dTRAF2 (Shen et al., 2001). Interestingly, dTRAF2 is required for Toll signalling in immunity, but is not essential for embryogenesis: as $d T R A F 2$ null mutant flies survive to adulthood (Cha et al., 2003).

In the absence of signalling, Dorsal is found in the cytoplasm in complex with IKB homologue

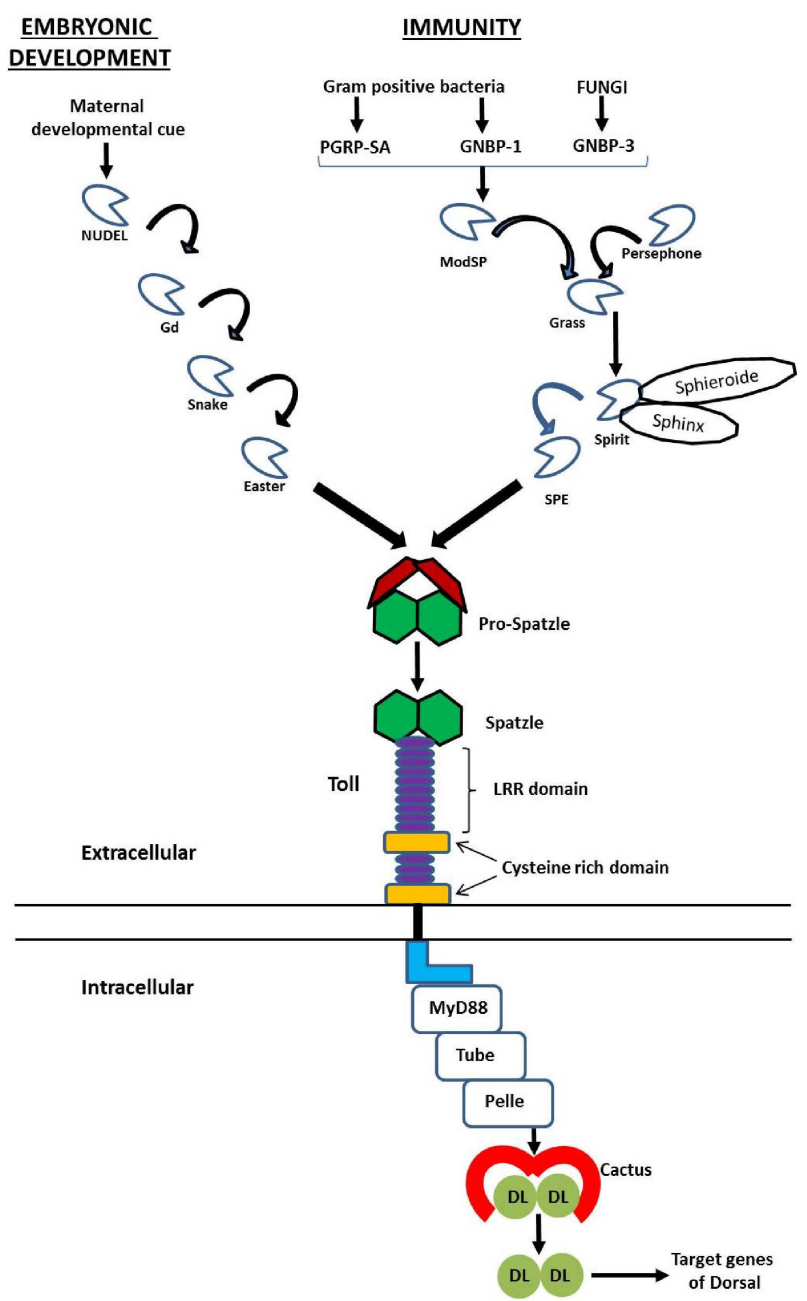

Fig. 1: The figure shows the activation of Toll pathway in embryonic development and immunity. Note that the difference is only in the signalling upstream to activation of Spz which is the ligand for Toll. During development Spz activation is through proteases Nudel, Gd, Snake and easter to SPE (Spz processing enzyme). While during immune response the $\mathrm{Spz}$ processing is through ModSP, Grass, Sphieroide pathway which activates SPE leading to processing of Spz. Signalling to SPE is through different PRRs (GNBP, PGRPs) which recognise different PAMPs (Beta 1,3-glucan, Lys type PGN etc). Activated Spz binds Toll receptor inducing structural changes which in turn activates the cytoplasmic TIR domain resulting in interaction with Death domain proteins MyD88, Tube and a kinase named Pelle. This is followed by phosphorylation of Cactus which in turn marks it for proteolytic degradation. This results in release of Dorsal/ DIF which enter the nucleus to regulate gene transcription

Cactus (Whalen and Steward, 1993). Activation of Toll signalling leads to the degradation of Cactus and the nuclear localisation of Dorsal to direct gene expression (Bergmann et al., 1996). The phosphorylation of both Dorsal and Cactus is required 
for the nuclear localisation of Dorsal (Gillespie and Wasserman, 1994; Drier et al., 1999). Phosphorylated Dorsal interacts with dNTF2 (Drosophila Nuclear Translocation Factor 2) and Nup88 to localise to the nucleus.

Once inside the nucleus, Dorsal/DIF rapidly activates AMPs, which are later released in the hemolymph (Hoffmann, 2003). AMPs are small, secreted, cationic peptides that can kill microbes or block their growth by disrupting membrane integrity (Hoffmann, 2003; Tanzi et al., 2010). AMP gene loci regulated by the Toll pathway have a single $\kappa B$ site characterized by a GGGAA consensus half site. While the regulation of target AMP genes by Dorsal/DIF upon microbial infection is well established, transcriptional regulation of Dorsal or DIF is not known. We found that in $d l^{l}$ mutant, expression of Dorsal protein was not detected (Mrinal and Nagaraju, 2010). This indicated towards a possible auto-regulation of $d l$ gene by Dorsal itself. Recently, we have explained the mechanism of auto-regulation for Dorsal (Mrinal and Nagaraju, 2010). We found that early in immune response, Dorsal induces transcription of its own gene by binding to a $\kappa B$ motif present in the first intron of $d l$ gene. However, in the later stages of immune response, Dorsal repositions itself to another binding site in the promoter of $d l$ gene (Mrinal and Nagaraju, 2010). Interestingly, Dorsal binding to the promoter $\kappa B$ motif results in transcriptional repression of $d l$. We have shown that the repressor function of Dorsal is due to co-operative interactions with a co-regulator AP-1 (Drosophila homologue) protein. This established the temporally regulated feedback loop in Dorsal auto-regulation (Mrinal and Nagaraju, 2010). Auto-activation and auto-repression of genes has been known for a long time. However, Dorsal auto-regulation is the first example of its kind, where both auto-activation and auto-repression of a gene is affected by the same transcription factor. We were puzzled to notice that the two $\kappa B$ motifs in the $d l$ gene bind the same transcription factor and still produce opposite outcomes. This prompted us to further explore the mechanism of $d l$ auto-regulation by Dorsal protein.

\section{Mechanism of Gene Activation and Repression by Dorsal}

Dorsal is a transcription factor belonging to $\mathrm{NF} \kappa \mathrm{B}$ family of proteins. TFs of this family can act both as activator and/or repressor of transcription. In Drosophila, Torso receptor tyrosine kinase signalling pathway, which is activated at the poles, selectively masks the ability of Dorsal to function as a transcriptional repressor at these positions (Rusch and Levine, 1994; Rusch and Levine 1996). Torso signalling modulates the ability of Capicua (Cic), Cut, and Dri, proteins that consequently influence the ability of Dorsal to function as a transcriptional repressor (Valentine et al., 1998; Jimenez et al., 2000). This suggests that activation or repression by Dorsal is dependent on a potential crosstalk with other pathways.

First, classical study based on the analysis of cis-regulatory sequences showed that Dorsal can function either as an activator or a repressor to control gene expression along the D-V axis (Jiang et al., 1993, Kirov et al., 1994). Dorsal, by default, is an activator of transcription in Drosophila and its repressor function is context-dependent, e.g., repression of zen by Dorsal was ascribed to cooperative interactions with DNA-binding proteins occupying associated ATrich sequences upstream of Dorsal binding site in the zen promoter (Kirov et al., 1993). It was also shown that repressor activity of Dorsal requires Groucho, a global co-repressor (Dubnicoff et al., 1997). We have already shown that, repressor activity of Dorsal was co-repressor dependent (Mrinal and Nagaraju, 2010). Both these studies have suggested that repressor function of Dorsal is co-regulator dependent. However, it has raised another query as to why Dorsal interaction with co-regulator is possible at few $\kappa B$ motifs but not on others?

\section{Role of Combinatorial Code in Target Gene Regulation by Dorsal}

Combinatorial interactions between Dorsal and other transcription factors were found to be important in spatio-temporal regulation of target gene expression. Synergistic DNA binding between Dorsal and Twist permits gene expression in more lateral regions of 
the embryo where, neither Dorsal nor Twist is capable of inducing gene expression alone (Gonzalez-Crespo and Levine, 1993 and 1994; Jiang et al., 1993; Stathopoulos and Levine, 2002). Furthermore, transcriptional repressors function to refine the expression domains produced by activators. For instance, to restrict rho expression to ventro-lateral stripes in the embryo, Dorsal and Twist activation is antagonized in ventral regions by the Snail repressor, resulting in the lateral stripe pattern of gene expression exhibited by these genes (Kosman et al., 1991; Ip et al., 1992). Advent of genomics has allowed scientists to dig further this concept of combinatorial regulation of Dorsal. Such studies have identified a set of 25 cis-regulatory sequences, which act in concert with Dorsal along the D-V axis (Stathopoulos and Levine, 2004; Markstein et al., 2004). Genome-wide studies employing ChIP-chip identified hundreds of binding sequences, including hitherto unknown binding motifs, for Dorsal and associated regulatory proteins in the $\mathrm{D}-\mathrm{V}$ patterning genes (Sandmann et al., 2007; Zeitlinger et al., 2007). For instance, apart from Dorsal-binding sequence in the target genes, the motif GCTGGYA was identified in enhancers that control expression in a broad lateral stripe. On the contrary, genes that expressed in the ventro-lateral stripes had CACATGT and RGGNCAG motifs nearby functional Dorsal motifs (Stathopoulos et al., 2002; Markstein et al., 2002; Markstein et al., 2004). The affinity of Dorsal-binding sites within cis-regulatory sequences is shown to influence the domain of target-gene expression (Jiang and Levine, 1993). A twi cis-regulatory sequence, which normally directs expression to ventral regions of the embryo, exhibited a dorsally expanded expression domain (i.e., the ventro-lateral domain) when the low affinity Dorsal-binding sites were mutated to high affinity ones. Such analysis reinforced the concept of "combinatorial codes" in Dorsal-mediated gene expression.

Main emphasis of this code is that activator and repressor function of Dorsal is modulated by other proteins depending on the high or low affinity of Dorsal for that particular motif (Valentine et al., 1998; Jimenez et al., 2000). All these studies have pointed to the fact that wide diversity in $\kappa B$ motif sequences is not without a reason and perhaps the sequence of the Dorsal-binding motif may have 'a' role in gene regulation and Dorsal function.

\section{Role of $\mathrm{\kappa B}$ Motif Sequence and Geometry in Gene Regulation by Dorsal}

In recent times, we have started to develop understanding towards the factors that discriminate activator function of Rel proteins from its repressor function. While studying the auto-regulation of Dorsal, we performed motif swap experiment and found that Dorsal interaction with AP-1 was specific for AGAAAAACA motif present in the promoter (Mrinal and Nagaraju, 2010). When this motif was replaced with canonical GGAAATTCC activator motif, co-repressor function of AP-1 was lost. The Dorsal-AP1 complex was not recruited, either in vitro or in vivo, with the canonical activator motif GGAAATTCC. This indicated that sequence of $\kappa B$ motif perhaps had some role to play in Dorsal interaction with its co-regulator (Mrinal and Nagaraju, 2010).

We explored this question further and showed that composition of the $\kappa B$ motif sequence has a key role to play in the interaction of co-regulator with Dorsal. We found that all known Dorsal target genes which are repressed by Dorsal, have an A-tract in the binding motif while none of the activator motifs had A-tract. Through molecular simulation studies, we have shown that $\kappa B$ core with A-tract (which is present in repressor motifs) is more deformable than activator $\kappa B$ core, which always lacks A-tract. We further showed that presence of ' $A$ ' or ' $T$ ' at the $6^{\text {th }}$ position in the nonameric $\kappa B$ motif is critical for imparting activator or repressor function (Mrinal and Nagaraju, 2010; Mrinal et al., 2011). While different activator motifs had comparable major groove geometry, the repressor motifs had distinct major groove geometry. Thus, binding of Dorsal to different repressor motifs is decided by the sequence of $\kappa B$ motif and the co-repressor (Mrinal et al., 2011). This suggests that DNA sequence can induce allosteric changes in the TF to enable its binding to the DNA motif. This led us to conclude that $\kappa B$ motifs in Drosophila exist in activator and repressor conformations, implying that there is a sequence 

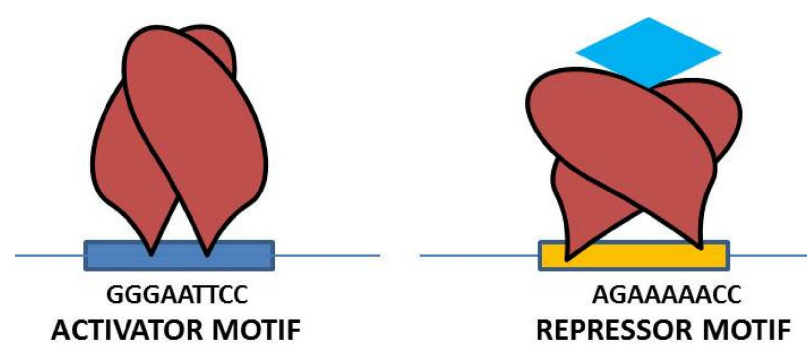

Fig. 2: Rel family transcription factors like Dorsal can take different conformations on different DNA sequences. As a result,on certain motifs Dorsal binds in association with co-regulator while on other sites it binds without cofactors. Thus, recruitment of co-regulator to Dorsal-DNA complex is allosterically controlled

encoded geometry in DNA binding motifs (Fig. 2). Later on, similar findings were made by Wang et al. as they found that sequence at the central position of the $\kappa B$ motif affects not only transcriptional activity of Rel proteins but also its ability to heterodimerize with other Rel proteins (Wang et al., 2012).

\section{Conclusion}

Study of Toll pathway in last three decades has greatly enhanced our knowledge of molecular mechanisms in D-V signalling and its regulation. In last few years, research in this field has focussed on understanding the Dorsal gradient formation and its gene regulatory network using high throughput technologies. This has expanded the number of target genes downstream to Toll and brought Dorsal into focus. The precise question to be answered for now is: How does Dorsal decide the qualitative and quantitative nature of target gene expression?

\section{References}

Anderson K V and Nüsslein-Volhard C (1984) Information for the dorsal-ventral pattern of the Drosophila embryo is stored as maternal mRNA Nature 311 223-227

Anderson K V, Jürgens G and Nüsslein-Volhard C (1985) Establishment of dorsal-ventral polarity in the Drosophila embryo: genetic studies on the role of the Toll gene product Cell 42 779-789

Ashburner M and Carson H L (1986) The genetics and biology of Drosophila Academic Press London, 3e
It is evident that ability of Dorsal to induce or repress gene expression is context-based. Understanding this 'context' is very crucial, since this will help in decoding the molecular basis of target gene recognition by transcription factors in general. Differential ability of Dorsal to bind many variants of $\kappa B$ motifs leading to different degrees of transcriptional expression of target genes indicates that, there cannot be a simple model of recognition codes of DNA-binding by Dorsal. Flexibility in protein-DNA interactions, selective role of coregulators and other effects of local and non-local parameters confound straightforward descriptions of DNA base preferences in Dorsal binding (Mrinal et al., 2011). Dorsal acts as a global regulator and the co-regulators act in gene specific manner. Since, Dorsal can interact with many co-regulators, this adds tremendously to its DNA-binding diversity (Stathopoulos and Levine, 2004; Markstein et al., 2004). Hence, to completely decipher the DNArecognition codes of Dorsal, high throughput technologies would be required which will help to gain insights into gene targeting in vivo. This will also help in understanding the role of DNA induced allostery, co-operative recruitment or combinatorial codes in Dorsal binding which will in turn help us to understand how specificity is imparted in gene regulation.

\section{Acknowledgements}

NM acknowledges financial support from INSA for the work published here.

Bakula M (1970) Antibacterial compounds in the cell-free haemolymph of Drosophila melanogasterJ Insect Physiol 16 185-197

Basset A, Khush R S, Braun A, Gardan L, Boccard F, Hoffmann J A and Lemaitre B (2000) The phytopathogenic bacteria Erwiniacarotovora infects Drosophila and activates an immune response Proc Natl Acad Sci USA 97 3376-3381

Bergmann A, Stein D, Geisler R, Hagenmaier S, Schmid B, Fernandez N, Schnell B and Nüsslein-Volhard C (1996) A gradient of cytoplasmic Cactus degradation establishes the nuclear localization gradient of the dorsal morphogen 
in Drosophila Mech Dev 60 109-123

Biemar F, Nix D A, Piel J, Peterson B, Ronshaugen M, Sementchenko V, Bell I, Manak J R and Levine M S (2006) Comprehensive identification of Drosophila dorsal-ventral patterning genes using a whole-genome tiling array Proc Natl Acad Sci USA 103 12763-12768

Boman H G, Nilsson I and Rasmuson B (1972) Inducible antibacterial defence system in Drosophila Nature $\mathbf{2 3 7}$ 232-235

Boman H G, Nilsson-Faye I, Paul K and Rasmuson Jr T (1974) Insect immunity I: Characteristics of an inducible cellfree antibacterial reaction in hemolymph of Samia cynthia pupae Infect Immun 10 136-145

Brennan C A and Anderson K V (2004) Drosophila: the genetics of innate immune recognition and response Annu Rev Immunol 22 457- 483

Buchon N, Poidevin M, Kwon H M, Guillou A, Sottas V, Lee B L and Lemaitre B (2009) A single modular serine protease integrates signals from pattern-recognition receptors upstream of the Drosophila Toll pathway Proc Natl Acad Sci USA 106 12442-12447

Carton Y and Nappi A J (1997) Drosophila cellular immunity against parasitoids Parasitol Today 13 218-227

Cho Y S, Stevens L M and Stein D (2010) Pipe-dependent ventral processing of Easter by Snake is the defining step in Drosophila embryo DV axis formation Curr Biol 201133 1137.

Delotto Y and Delotto R (1998) Proteolytic processing of the Drosophila Spätzle protein by easter generates a dimeric NGF-like molecule with ventralising activity Mech Dev 72 141-148

Dissing M, Giordano H and Delotto R (2001) Autoproteolysis and feedback in a protease cascade directing Drosophila dorsal-ventral cell fate EMBO J 20 2387-2393

Drier E A, Huang L H and Steward R (1999) Nuclear import of the Drosophila Rel protein Dorsal is regulated by phosphorylation Genes Dev 13 556-568

Dubnicoff T, Valentine S A, Chen G, Shi T, Lengyel J A, Paroush $\mathrm{Z}$ and Courey A J (1997) Conversion of dorsal from an activator to a repressor by the global corepressor Groucho Genes Dev 11 2952-2957

El Chamy L, Leclerc V, Caldelari I and Reichhart J M (2008) Sensing of 'danger signals' and pathogen-associated molecular patterns defines binary signalling pathways 'upstream' of Toll Nat Immunol 9 1165-1170

Ferrandon D, Imler J L, Hetru C and Hoffmann J A (2007) The Drosophila systemic immune response: sensing and signalling during bacterial and fungal infections Nat Rev

\section{Immunol 7 862-874}

Fortini M E, Skupski M P, Boguski M S and Hariharan I K (2000) A survey of human disease gene counterparts in the Drosophila genome $J$ Cell Biol 150 F23-F30

Gangloff M, Murali A, Xiong J, Arnot C J, Weber A N, Sandercock A M, Robinson C V, Sarisky R, Holzenburg A, Kao C and Gay N J (2008) Structural insight into the mechanism of activation of the Toll receptor by the dimeric ligand Spätzle J Biol Chem 283 14629-14635

Gay N J and Gangloff M (2007) Structure and function of Toll receptors and their ligands Annu Rev Biochem 76 141165

Georgel P, Naitza S, Kappler C, Ferrandon D, Zachary D, Swimmer C, Kopczynski C, Duyk G, Reichhart J M and Hoffmann J A (2001) Dev Cell 1 503-514

Gerttula S, Jin Y S and Anderson K V (1988) Zygotic expression and activity of the Drosophila Toll gene, a gene required maternally for embryonic dorsal-ventral pattern formation Genetics 119 123-33

Gillespie S K and Wasserman S A (1994) Dorsal, a Drosophila Rel-like protein, is phosphorylated upon activation of the transmembrane protein Toll Mol Cell Biol 14 3559-3568

González-Crespo S and Levine M (1993) Interactions between dorsal and helix-loop-helix proteins initiate the differentiation of the embryonic mesoderm and neuroectoderm in Drosophila Genes Dev 7 1703-1713

González-Crespo S and Levine M (1994) Related target enhancers for dorsal and NF-kappa B signaling pathways Science $264255-258$

Gottar M, Gobert V, Matskevich A A, Reichhart J M, Wang C, Butt T M, Belvin M, Hoffmann J A and Ferrandon D (2006) Dual detection of fungal infections in Drosophila via recognition of glucans and sensing of virulence factors Cell 127 1425-1437

Halfon M S, Hashimoto C and Keshishian H (1995) The Drosophila toll gene functions zygotically and is necessary for proper motoneuron and muscle development Dev Biol 169 151-167

Han J H, Lee S H, Tan Y Q, Lemosy E K and Hashimoto C (2000) Gastrulation defective is a serine protease involved in activating the receptor toll to polarize the Drosophila embryo Proc Natl Acad Sci USA 97 9093-9097

Han Z S and Ip Y T (1999) Interaction and specificity of Relrelated proteins in regulating Drosophila immunity gene expression J Biol Chem 274 21355-21361

Hashimoto C, Gerttula S and Anderson K V (1991) Plasma membrane localization of the Toll protein in the syncytial Drosophila embryo: importance of transmembrane 
signaling for dorsal-ventral pattern formation Development 111 1021-1028

Hecht P M and Anderson K V (1993) Genetic characterization of tube and pelle, genes required for signaling between Toll and dorsal in the specification of the dorsal-ventral pattern of the Drosophila embryo Genetics 135 405-417

Hoffmann J A (2003) The immune response of Drosophila Nature $426 \quad 33-38$

Hong J W, Hendrix D A, Papatsenko D and Levine M S (2008) Proc Natl Acad Sci USA 105 20072-20076

Huang A M, Rusch J and Levine M (1997) Ananteroposterior Dorsal gradient in the Drosophila embryo Genes Dev 11 1963-1973

Huang H R, Chen Z J, Kunes S, Chang G D and Maniatis T (2010) Endocytic pathway is required for Drosophila Toll innate immune signaling Proc Natl Acad Sci USA 107 $8322-8327$

Hultmark D (2003) Drosophila immunity: paths and patterns Curr Opin Immunol 15 12-19

Imler J L and Bulet P (2005) Antimicrobial peptides in Drosophila: structures, activities and gene regulation Chem Immunol Allergy 86 1-21

Imler J L, Ferrandon D, Royet J, Reichhart J M, Hetru C and Hoffmann J A (2004) Toll-dependent and Toll-independent immune responses in Drosophila J Endotoxin Res 10241 246

Ip Y T, Kraut R, Levine M and Rushlow C A (1991) The dorsal morphogen is a sequence-specific DNA-binding protein that interacts with a long-range repression element in Drosophila Cell 64 439-446

Irving P, Troxler L, Heuer T S, Belvin M, Kopczynski C, Reichhart J M, Hoffmann J A and Hetru C A (2001) genome-wide analysis of immune responses in Drosophila Proc Natl Acad Sci USA 98 15119-15124

Jang I H, Chosa N, Kim S H, Nam H J, Lemaitre B, Ochiai M, Kambris Z, Brun S, Hashimoto C, Ashida M, Brey P T and Lee W J (2006) A Spätzle-processing enzyme required for toll signaling activation in Drosophila innate immunity Dev Cell 10 45-55

Jiang J, Cai H, Zhou Q and Levine M (1993) Conversion of a dorsal-dependent silencer into an enhancer: evidence for dorsalcorepressors EMBO J 12 3201-3209

Jiang J, Rushlow C A, Zhou Q, Small S and Levine M (1992) Individual dorsal morphogen binding sites mediate activation and repression in the Drosophila embryo $E M B O$ J 11 3147-3154

Jiménez G, Guichet A, Ephrussi A and Casanova J (2000) Relief of gene repression by torso RTK signaling: role of capicua in Drosophila terminal and dorsoventral patterning Genes Dev 14 224-231

Kambris Z, Bilak H, D'alessandro R, Belvin M, Imler J L and Capovilla M (2003) DmMyD88 controls dorsoventral patterning of the Drosophila embryo EMBO Rep 4 64-69

Kambris Z, Brun S, Jang I H, Nam H J, Romeo Y, Takahashi K, Lee W J, Ueda R and Lemaitre B (2006) Drosophila immunity: a large-scale in vivo RNAi screen identifies five serine proteases required for Toll activation Curr Biol 16 808-813

Kimbrell D A and Beutler B (2001) The evolution and genetics of innate immunity. Nat Rev Genet 2 256-267

Kirov N, Childs S, O'Connor M and Rushlow C (1994) The Drosophila dorsalmorphogen represses the tolloid gene by interacting with a silencer element $\mathrm{Mol}$ Cell Biol 14 713-722

Kirov N, Zhelnin L, Shah J and Rushlow C (1993) Conversion of a silencer into an enhancer: evidence for a co-repressor in dorsal-mediated repression in Drosophila EMBO J 12 3193-3199

Kosman D, Ip Y T, Levine M and Arora K (1991) Establishment of the mesoderm-neuroectoderm boundary in the Drosophila embryo Science 254 118-122

Lemaitre B, Nicolas E, Michaut L, Reichhart J M and Hoffmann J A (1996) The dorsoventral regulatory gene cassette spätzle/Toll/cactus controls the potent antifungal response in Drosophila adults Cell 86 973-983

Lemaitre B, Reichhart J M and Hoffmann J A (1997) Drosophila host defense: differential induction of antimicrobial peptide genes after infection by various classes of microorganisms Proc Natl Acad Sci USA 26 14614-14619

Lemosy E K, Kemler D and Hashimoto C (1998) Role of Nudel protease activation in triggering dorsoventral polarization of the Drosophila embryo Development 125 4045-4053

Levashina E A, Langley E, Green C, Gubb D, Ashburner M, Hoffmann J A and Reichhart J M (1999) Constitutive activation of toll-mediated antifungal defense in serpindeficient Drosophila Science 285 1917-1919

Ligoxygakis P, Pelte N, Hoffmann J A and Reichhart J M (2002) Activation of Drosophila Toll during fungal infection by a blood serine protease Science 297 114-116

Manfruelli P, Reichhart J M, Steward R, Hoffmann J A and Lemaitre B (1999) A mosaic analysis in Drosophila fat body cells of the control of antimicrobial peptide genes by the Rel proteins Dorsal and DIF EMBO J 18 33803391

Markstein M, Markstein P, Markstein V and Levine M (2002) Genome-wide analysis of clustered Dorsal binding sites 
identifies putative target genes in the Drosophila embryo Proc Natl Acad Sci USA 99 763-768

Markstein M, Zinzen R, Markstein P, Yee KP, Erives A, Stathopoulos A and Levine M (2004) A regulatory code for neurogenic gene expression in the Drosophila embryo Development 131 2387-2394

Medzhitov R, Preston-Hurlburt P and Janeway Jr C A (1997) A human homologue of the Drosophila Toll protein signals activation of adaptive immunity Nature $\mathbf{3 8 8} 394-397$

Meng X, Khanuja B S and Ip Y T (1999) Toll receptor-mediated Drosophila immune response requires Dif, an NF-kappaB factor Genes Dev13 792-797

Mrinal N and Nagaraju J (2010) Dynamic repositioning of dorsal to two different kappaB motifs controls its autoregulation during immune response in Drosophila J Biol Chem 285 24206-24216

Mrinal N, Tomar A and Nagaraju J (2011) Role of sequence encoded $\kappa B$ DNA geometry in gene regulation by Dorsal Nucleic Acids Res 39 9574-9591

Nüsslein-Volhard C and Wieschaus E (1980) Mutations affecting segment number and polarity in Drosophila Nature $\mathbf{2 8 7}$ 795-801

Reach M, Galindo R L, Towb P, Allen J L, Karin M and Wasserman S A (1996) A gradient of cactus protein degradation establishes dorsoventral polarity in the Drosophila embryo Dev Biol 180 353-364

Rusch J and Levine M (1994) Regulation of the dorsalmorphogen by the Toll and torso signaling pathways: a receptor tyrosine kinase selectively masks transcriptional repression Genes Dev 8 1247-1257

Rusch J and Levine M (1996) Threshold responses to the dorsal regulatory gradient and the subdivision of primary tissue territories in the Drosophila embryo Curr Opin Genet Dev 6 416-423

Rutschmann S, Jung A C, Hetru C, Reichhart J M, Hoffmann J A and Ferrandon D (2000) The Rel protein DIF mediates the antifungal but not the antibacterial host defense in Drosophila Immunity 12 569-580

Sandmann T, Girardot C, Brehme M, Tongprasit W, Stolc V and Furlong E E (2007) A core transcriptional network for early mesoderm development in Drosophila melanogaster Genes Dev 21 436-449

Schneider D S, Jin Y, Morisato D and Anderson K V (1994) A processed form of the Spätzle protein defines dorsalventral polarity in the Drosophila embryo Development 120 1243-1250

Shen B, Liu H, Skolnik E Y and Manley J L (2001) Physical and functional interactions between Drosophila TRAF2 and
Pelle kinase contribute to Dorsal activation Proc Natl Acad Sci USA 98 8596-8601

Shen B, Liu H, Skolnik E Y and Manley J L (2001) Physical and functional interactions between Drosophila TRAF2 and Pelle kinase contribute to Dorsal activation Proc Natl Acad Sci USA A 98 8596-8601

Soderhall K and Cerenius L (1998) Role of the prophenoloxidaseactivating system in invertebrate immunity Curr Opin Immunol 10 23-28

Stathopoulos A, Tam B, Ronshaugen M, Frasch M and Levine M (2004) pyramus and thisbe: FGF genes that pattern the mesoderm of Drosophila embryos Genes Dev 18 687-699

Stathopoulos A, Van Drenth M, Erives A, Markstein M and Levine M (2002) Whole-genome analysis of dorsal-ventral patterning in the Drosophila embryo Cell 111 687-701

Stein D S and Stevens L M (1991) Establishment of dorsal-ventral and terminal pattern in the Drosophila embryo Curr Opin Genet Dev $1247-254$

Sun H, Bristow BN, Qu G and Wasserman SA 2002. A heterotrimeric death domain complex in Toll signaling. Proc Natl Acad Sci USA 99 12871-6

Tanji T, Yun E Y and Ip Y T (2010) Heterodimers of NF-kappaB transcription factors DIF and Relish regulate antimicrobial peptide genes in Drosophila Proc Natl Acad Sci USA 107 $14715-14720$

Tzou P, De Gregorio E and Lemaitre B (2002) How Drosophila combats microbial infection: a model to study innate immunity and host-pathogen interactions Curr Opin Microbiol 5 102-110

Valentine S A, Chen G, Shandala T, Fernandez J, Mische S, Saint R and Courey A J (1998) Dorsal-mediated repression requires the formation of a multiprotein repression complex at the ventral silencer Mol Cell Biol 18 65846594

Vierstraete E, Verleyen P, Baggerman G, D'Hertog W, Van den Bergh G, Arckens L, De Loof A and Schoofs L (2004) A proteomic approach for the analysis of instantly released wound and immune proteins in Drosophila melanogaster hemolymph Proc Natl Acad Sci USA 101 470-475

Wang V Y, Huang W, Asagiri M, Spann N, Hoffmann A, Glass C and Ghosh G (2012) The transcriptional specificity of NF$\kappa B$ dimers is coded within the $\kappa B$ DNA response elements Cell Rep 2 824-839

Weber A N, Tauszig-Delamasure S, Hoffmann J A, Lelièvre E, Gascan H, Ray K P, Morse M A, Imler J L and Gay N J (2003) Binding of the Drosophila cytokine Spätzle to Toll is direct and establishes signaling Nat Immunol 4 794800 
Whalen A M and Steward R (1993) Dissociation of the dorsalcactus complex and phosphorylation of the dorsal protein correlate with the nuclear localization of dorsal J Cell Biol 123 523-534

Zeitlinger J, Zinzen R P, Stark A, Kellis M, Zhang H, Young R A and Levine M (2007) Whole-genome ChIP-chip analysis of Dorsal, Twist, and Snail suggests integration of diverse patterning processes in the Drosophila embryo Genes Dev 21 385-390

Zhu X, Sen J, Stevens L, Goltz J S and Stein D (2005) Drosophila pipe protein activity in the ovary and the embryonic salivary gland does not require heparan sulphate glycosaminoglycans Development 132 3813-3822. 